\title{
Necessidade de motivação para alteração das alíquotas no imposto de importação ${ }^{1}$
}

\author{
André Fustaino Costa ${ }^{2}$ \\ Valdeir Ribeiro de Jesus ${ }^{3}$
}

\begin{abstract}
Resumo
Analisa-se, sob o enfoque da regra matriz de incidência fiscal, a necessidade de motivação para a alteração de alíquotas pelo Poder Executivo, através de Decretos no âmbito do Imposto de Importação. Tais são os meios utilizados pelo Poder Executivo para a alteração das alíquotas e, como atos administrativos que são necessitam obrigatoriamente de motivação a fim de dificultar atos absolutamente discricionários por parte do Administrador Público e anulação pelo Judiciário ante a ilegalidade ínsita ao ato.
\end{abstract}

Palavras-Chave: Imposto de importação; Ato administrativo; Decreto; Motivação.

\section{Introdução}

Dentre os impostos federais, ao lado da exportação, tem-se o imposto de importação.

Atuando sobre a relação jurídica da pessoa física ou jurídica que objetiva introduzir produto não-nacional (estrangeiro) ou desnacionalizado, a Constituição Federal de 1988 estabelece o Imposto de Importação e confere competência à União.

Certa singularidade encontra este imposto em relação aos demais. Características estas que motivam o estudo acerca do mesmo e da legalidade de atos praticados pela autoridade administrativa competente em matéria de importação (a União), principalmente focando-se a motivação enquanto elemento obrigatório destes atos.

Artigo apresentado à Disciplina de Direito Tributário, ministrada pela Profa. Marlene Kempfer Bassoli Graduando em Direito pela Universidade Estadual de Londrina. E-mail: andrepira5@yahoo.com.br. Graduando em Direito pela Universidade Estadual de Londrina. E-mail: ribeiro_vj@yahoo.com.br. 


\section{Conceito e características}

O Imposto de Importação é o imposto de competência da União, que tem por finalidade a proteção industrial nacional, configurando-se, assim, instrumento de política econômico-governamental.

Preocupado com a dinâmica das indústrias nacionais e diante do mercado exterior a oferecer produtos similares aos dos nacionais ou, produtos inexistentes na produção industrial nacional, ou ainda, produtos de qualidade diferenciada, a União, em razão do pacto federativo, promove a regulamentação deste imposto. Resta, então, caracterizado que o Imposto de Importação tem principalmente uma função mais extrafiscal que arrecadatória (função fiscal dos impostos).

Extrafiscal porque está vocacionada a atuar como elemento de ação governamental, na área do comércio exterior, no domínio das políticas econômica, monetária e cambial, caracterizando-se o Imposto de Importação como instrumento de proteção da indústria nacional.

O desprezo à finalidade arrecadatória, diferencial deste imposto frente aos demais, é verificável na prática de alteração das alíquotas em função do comércio exterior. Exemplo tem-se na fixação da alíquota observada a natureza da mercadoria ou produto.

Num juízo valorativo, a União estabelece alíquotas diferentes, conforme a essencialidade do produto, já consagrando a extrafiscalidade e protecionista à indústria nacional e, de certa forma, negatória à política arrecadatória visto que ao praticar determinada alíquota em função da essencialidade do bem, a União protege a indústria nacional deixa de arrecadar a cifra que arrecadaria se tal posição desincentivadora de consumo não tomasse.

A questão recai em como estabelecer as alíquotas para cada situação, atentando para a legalidade que deve permear os atos administrativos.

\section{Regra-matriz de incidência fiscal do imposto de importação}

A todos os impostos aplica-se a regra-matriz de incidência fiscal para fins de identificação dos elementos constantes nos textos legais que compõem a norma jurídica tributária. Diferente não poderia ocorrer com o Imposto de Importação. 
Ao respeitarem, os tributos, uma estruturação padrão na construção da norma jurídica do referido tributo têm possibilitado uma melhor delimitação do tributo, podendose identificar a qual espécie pertence e, quais os fatos da vida são alcançados enquanto constituidores das hipóteses de incidência tributaria.

A divisão em dá-se em hipótese tributária e relação jurídica tributária, como componentes da norma de direito material. Descabe, no momento, a análise de toda estrutura normativa.

\subsection{Hipótese tributária}

Na norma de direito material, enquanto antecedente tem-se a hipótese tributária, figurando a relação jurídica tributária como conseqüente lógico.

Compõe Hipótese tributária dos seguintes critérios para fins de identificação dos tributos em todos os elementos que o compõem: critério material, critério espacial e critério temporal.

Atentando para a composição da hipótese tributária do Imposto de Importação tem-se:

\subsubsection{Critério material}

O critério material apresenta a ação que pode assumir o sujeito passivo da relação, consistente em importar, trazer do exterior, produtos estrangeiros ou desnacionalizados, com a finalidade de uso ou consumo no Brasil.

\subsubsection{Critério espacial}

O critério temporal fixa o espaço, localiza numa região geográfica real ou ficta a prática (consumação) do critério material, consistindo, no imposto em epígrafe, no espaço referente ao território nacional, nos termos do Art. 19 , do CTN, bem como do Art. $1^{\circ}$ do Decreto n. 37/66. Entenda-se, por território nacional todo o espaço no qual determinado país possa exercer sua soberania, seja ele, terrestre, aéreo ou marítimo. 


\subsubsection{Critério temporal}

O critério temporal permite a determinação do momento em que considerasse praticado o critério material da hipótese tributária, a partir do qual juridicamente se estabelece uma relação. É, neste caso, o momento da entrada do produto estrangeiro no território nacional.

\subsection{Relação jurídica tributária}

Já na relação jurídica têm-se presentes os seguintes critérios: pessoal e quantitativo.

\subsubsection{Critério pessoal}

No critério pessoal se identificam as partes da relação jurídica estabelecida, ou seja, o sujeito ativo e o sujeito passivo. No Imposto de Importação essas pessoas são, respectivamente, a União; e, o contribuinte (em regra) ou o equiparado por lei, ou, ainda os responsáveis nos termos da lei.

\subsubsection{Critério quantitativo}

No critério quantitativo tem-se a mensuração do tributo, utilizando-se por elementos a base de cálculo e a alíquota.

Entenda-se a base de cálculo como o valor da transação da qual decorre a importação, assim entendido o preço efetivamente pago ou a pagar pelos produtos importados.

A alíquota é havida como a relação entre o montante da riqueza tributável e o valor do imposto que está sendo cobrado em função dela.

\section{Alteração da alíquota no imposto de importação via decreto (ato administrativo tributário)}

Inicialmente pode-se afirmar que os atos administrativos são sempre atos jurídicos, porque humanos e não apenas simples fenômenos da natureza. 
Somente as manifestações de vontade da Administração, agindo como Administração Pública, ou seja, em relações jurídicas de direito público, são consideradas atos administrativos.

Assim, podemos adotar o conceito elaborado por Hely Lopes Meireles (apud ALEXANDRINO; PAULO, 2006, p. 301), segundo o qual

ato administrativo é toda manifestação unilateral de vontade da Administração Pública, que agindo nesta qualidade, tem por fim imediato adquirir, resguardar, transferir, modificar, extinguir e declarar direitos, ou impor obrigações aos administrados ou a si própria.

Merece lavra, ainda, a definição de ato administrativo de Celso Antônio Bandeira de Mello (apud ALEXANDRINO; PAULO, 2006, p. 301):

Declaração do Estado (ou de quem lhe faça as vezes - como, por exemplo, um concessionário de serviço público), no exercício de prerrogativas públicas, manifestada mediante providências jurídicas complementares da lei a título de lhe dar cumprimento, e sujeitas a controle de legitimidade por órgão jurisdicional.

Os atos administrativos dividem-se nas seguintes espécies: atos normativos, atos ordinatórios, atos negociais, atos enunciativos e atos punitivos. Dentre esses, interessa destacar os atos normativos.

Atos normativos são aqueles que contém comandos gerais e abstratos aplicáveis a todos os administrados que se enquadrem nas situações neles previstas. Possuem conteúdo análogo ao das leis, com a principal diferença de não poderem inovar no ordenamento jurídico, criando direitos ou deveres para os administrados que não se encontrem previstos em lei.

Os atos normativos são, basicamente, introduzidos no ordenamento jurídico através de decretos, resoluções, instruções normativas, regimentos e regulamentos. Os primeiros são emitidos pelo chefe do Executivo (presidente da república, governadores e prefeitos).

Assim como as leis, há possibilidade de decretos atuarem na esfera tributária. É o caso do imposto de importação que constitui certa mitigação do princípio da legalidade, ou seja, a lei transfere uma parte de suas atribuições para serem estabelecidas por este instrumento introdutório de normas, nos termos do Art. 150, I, da CF, visto que suas 
alíquotas podem ser elevadas ou reduzidas, dentro dos limites fixados em lei, por ato do Poder Executivo.

Há, ainda, no imposto de importação, uma exceção ao princípio da anterioridade da lei ao exercício da lei financeiro. As alíquotas podem sofrer variações no curso do exercício financeiro, nos termos do Art. 150, $\S 1^{\circ}$, da CF, perfazendo-se tais alterações via decreto do chefe do Executivo, sendo, no presente imposto, o Presidente da República. Tal é a explicação doutrinária:

A Constituição Federal estabelecera a faculdade do Poder Executivo, atendidas as condições e os limites estabelecidos em lei, de alterar a alíquota do imposto de importação. Para tanto, torna-se obrigatória a prévia edição de lei (ato do Congresso Nacional), conferindo ao Executivo (Presidente da República) o poder de graduar as alíquotas específicas para cada tipo de produto dentro de limites (máximo e mínimo), fixando o âmbito (parâmetro) de atuação do Executivo (MELO, 2003, p. 64).

Estabelece a Constituição Federal de 1988, no seu art. 153 § 1ㅇ, que a alteração das alíquotas do Imposto de Importação pode ser alterada de acordo com limites estabelecidos em lei, a fim de ajustá-los aos objetivos da política cambial e do comércio exterior, ou seja, o Executivo só pode atuar no espaço e limite estabelecido em lei.

Realmente, o Executivo não tem o poder de inovar a ordem jurídica, não podendo estabelecer normas que disponham sobre criação, modificação e extinção dos tributos, em atendimento ao princípio da estrita legalidade tributária. Considerando que a lei (emanada do Legislativo) contém os elementos básicos da norma de tributação, atribui-se ao Executivo apenas a faculdade de expedir regras para possibilitar sua operacionalidade, fixando deveres meramente administrativos.

Acerca dos limites mínimo e máximo para alteração das alíquotas do Imposto de Importação, dispõe o art. 30 da Lei n. 3.244/57:

Poderá ser alterada dentro dos limites mínimo e máximo do respectivo capítulo, a alíquota relativa a produto;

a) cujo nível tarifário venha a se revelar insuficiente ou excessivo ao adequado cumprimento dos objetivos da Tarifa;

b) cuja produção interna for de interesse fundamental estimular;

c) que haja obtido registro de similar;

d) de país que dificultar a exportação brasileira para seu mercado, ouvindo previamente o Ministro das Relações Exteriores; 
e) de país que desvalorizar sua moeda ou conceder subsídio à exportação, de forma a frustrar objetivos da Tarifa.

Ou seja, tal poder de variação das alíquotas pelo Poder Executivo é medida que objetiva acelerar o comércio internacional, munido esse poder de instrumentos ágeis para permitir o flexionamento das alíquotas de modo a dificultar, ou incrementar, o fluxo de importações, incentivando a indústria nacional, amoldando-se ao entendimento de que o Imposto de Importação tem função predominantemente extrafiscal, sendo valioso instrumento de política econômica.

Evidente que aguardar-se edição de nova lei para majorar, ou minorar, o imposto de importação (pela via das modificações das alíquotas) não permitiria que fossem atendidos os referidos interesses governamentais.

Com relação ao poder das alíquotas como instrumento de política econômica, estas devem variar conforme sua essencialidade.

Embora não o digam expressamente nem a Constituição Federal nem o Código Tributário Nacional, as alíquotas do Imposto de Importação devem variar conforme a essencialidade do produto, com o que se estará pondo em prática o princípio da capacidade contributiva. Dependendo do produto, uma mercadoria de luxo, por exemplo, as alíquotas são em geral muito elevadas, exatamente para dificultar a entrada do produto no território nacional e dar, deste modo, melhores condições do produto nacional competir tanto no mercado interno como no externo.

\section{Necessidade de motivação pelo executivo para alterar a alíquiota do imposto de importação}

A alteração das alíquotas não é ato discricionário pelo Poder Executivo. A fundamentação da majoração há de ser válida, com indicação expressa e específica do objetivo a ser alcançado. Não basta a indicação genérica, como tem acontecido, dizendo-se que a alteração se faz para ajustar o imposto aos objetivos da política cambial e do comercio exterior. O objetivo a ser alcançado tem de ser indicado expressamente, sob pena de invalidação do ato, que sem essa indicação específica se revela discricionário, o que não se pode admitir, sem ofensas ao sistema jurídico, no qual a tributação rege-se pelo princípio da legalidade, e a cobrança do tributo é atividade administrativa plenamente vinculada 
Em matéria tributária não se admite qualquer discricionarismo, especialmente no que diz respeito à determinação do valor a ser cobrado. O valor do tributo há de ser determinado, em regra, com os elementos definidos em lei. A faculdade conferida ao Executivo para a alteração das alíquotas é excepcional.

No exercício dessa faculdade excepcional, o Poder Executivo não pode agir discricionariamente. $\mathrm{Na}$ arrecadação de tributo não se admite ato discricionário, pois ele deve ser exigido nos termos exatos da lei fiscal.

Ou seja, em outras palavras, como a alteração das alíquotas pelo Executivo se faz mediante Decreto, o qual é um ato administrativo, necessário se faz a publicação de motivação, um dos atributos do ato administrativo, sejam atos vinculados, sejam atos discricionários.

A doutrina dos administrativistas é pacífica, afirmando a necessidade de motivação dos atos administrativos.

Celso Antonio Bandeira de Mello (apud MACHADO, 2003, p. 301), reportando-se ao princípio da publicidade, afirma:

Consagra-se nisto o dever administrativo de manter plena transparência em seus comportamentos. Não pode haver em um Estado Democrático de Direito, no qual o pode reside no povo (art. 1ำ, parágrafo único, da constituição), ocultamento aos administrados dos assuntos a que todos interessam, e muito menos em relação aos sujeitos individualmente afetados por alguma medida.

E ao examinar o princípio da motivação, segundo o qual todos os atos administrativos devem ser motivados, o mesmo jurista ensina:

Dito princípio implica para a administração o dever de justificar seus atos, apontando-Ihes os fundamentos de direito e de fato, assim como a correlação lógica entre os eventos e situações que deu por existentes e a providência tomada, nos casos em que esse último aclaramento seja necessário para aferir-se a consonância da conduta administrativa com a lei que lhe serviu de arrimo (MELLO apud MACHADO, 2003, p. 301).

Não é outro o ensinamento de Juarez Freitas (apud MACHADO, 2003, p. 303-304):

Indubitavelmente, devem os atos administrativos ser motivados, em analogia com o que sucede na prática dos atos jurisdicionais, excetuados, quiçá, os de mero expediente e os ordinários de feição interna, quando autocompreensivos na sua 
expedição, designadamente na hipótese dos vinculados, ainda que sempre conveniente alguma fundamentação. Em sintonia com a mais acertada orientação, sobreleva e se faz inescapável o dever de motivar tratando-se dos atos discricionários, já que os vinculados, em boa parte das vezes, poderão licitamente sobreviver sem o cumprimento estrito de tal regra que deflui da Lei Maior. Na perspectiva adotada, é exatamente na consecução daqueles atos administrativos, que mais aparentemente reservam liberdade ao legislador, onde maior deverá ser a cobrança da devida fundamentação. Mais: ainda que a lei (contra a qual, por certo, militariam fortes indícios de inconstitucionalidade) dispensasse a motivação dos atos discricionários, esta seria uma obrigatoriedade descendente diretamente da Constituição, mais precisamente do núcleo fundante de seus princípios. De tal sorte, aplica-se ao legislador, agente do Poder Público, a regra constitucional expressamente atribuída ao juiz no exercício da tutela jurisdicional (e aos tribunais, inclusive, no âmbito de sua decisões administrativas) que impõe o dever de motivar compulsoriamente e sob pena de nulidade, os atos de discricionariedade vinculada no intuito $d$ verdadeiramente coibir o desvio de poder.

Tal proposição resulta irretorquível quando se aceita que, na prática de todo e qualquer ato administrativo, o que se verifica é a inexistência de liberdade irrestrita. A liberdade, negativa ou positivamente considerada, somente pode ser aquela que, por assim dizer, decorre da vontade do sistema, bem como de sua abertura ou ínsita indeterminação. Esta se assinale de passagem, não é de pequena monta, pois são múltiplas e sugestivas as possibilidades de aplicação do Direito ainda que reduzidíssimas no mais completamente vinculados dos atos. Toda a possibilidade, em maior ou menor escala, contudo, devem guardar fundamentações na regularidade do sistema, para evitar dois fenômenos simétricos e igualmente nocivos: de uma parte, uma noção de vinculatividade dissociada da subordinação a outro princípio da estrita legalidade e, de outra, uma noção de discricionariedade tendente a dar as costas à vinculação ao sistema, minando, pela arbitrariedade, a sua fundamentada abertura.

A jurisprudência é uníssona quanto à necessidade de motivação. Nesse sentido o julgado do Colendo Supremo Tribunal Federal:

Ementa: O STF já firmou entendimento de que o Conselho de Política Aduaneira, ao fixar a pauta de valor mínimo nos termos dos arts. 9 e 22, d, ambos da Lei $n$. $3.244 / 57$, deve motivar sua resolução editada para esse fim, por causa do princípio da legalidade que domina a formação de qualquer ato administrativo, não podendo, assim, o referido órgão, determinar aquela pauta sem fundamentar-se na intercadência ou no 'dumping' a que se reporta a primeira norma supracitada (STF, RE 76.601, Rel. Ministro Antonio Nader, j. 12.09.1978, DJU de 06.10.1978.) (MACHADO, 2003, p. 307).

Ou seja, não cabe motivação genérica, tal não pode ser admitida como suficiente para a validade de um ato administrativo (Decreto) que venha a alterar a alíquota do Imposto de Importação. A ser assim, conceder-se-á carta branca ao Executivo, para praticar abusos e desvios inevitáveis, já que inevitavelmente, haverá a concentração dos poderes de legislar e administrar. 


\section{Considerações finais}

Em sendo o decreto um ato administrativo, necessariamente, deve conter motivação no ato de sua publicação. Tal exposição de motivos deve ser, ainda, fundamentada, de modo a demonstrar ao contribuinte as circunstâncias de maneira objetiva e específica, não sendo suficiente a mera referência às conveniências de mercado ou expressão igualmente vaga.

\section{Referências}

ALEXANDRINO, Marcelo ; PAULO, Vicente. Direito administrativo. 10. ed. Rio de Janeiro: Editora Impetus, 2006.

CASSONE, Vittorio. Direito tributário. 16. ed. São Paulo: Atlas, 2004.

FABRETTI, Laudio Camargo. Código tributário nacional comentado. 6. ed. São Paulo: Atlas, 2005.

MACHADO, Hugo de Brito. Comentários ao código tributário nacional. São Paulo: Atlas, 2003.

. Curso de direito tributário. 25. ed. São Paulo: Malheiros Editores, 2004.

MAFRINATO, Paulino. Imposto de importação: uma análise do lançamento e fundamentos. São Paulo: Aduaneiras, 2004.

MARTINS, Ives Gandra da Silva. Comentários ao código tributário nacional. 3. ed. São Paulo: Saraiva, 2002.

Curso de direito tributário. 8. ed. São Paulo: Saraiva, 2001.

MELO, José Eduardo Soares de. A importação no direito tributário: impostos, taxas, contribuições. São Paulo: Editora Revista dos Tribunais, 2003.

SILVA, Volney Zanenhof de Oliveira (Coord.). Código tributário nacional: lei 5172, de 25 de outubro de 1966: comentado e anotado. 3. ed. Campinas: CS Edições, 2003. 